\title{
Resistência a antimicrobianos e sua correlação estatística com o consumo em hospitais: Uma revisão integrativa da literatura
}

\author{
Antimicrobial resistance and its statistical correlation with consumption in hospitals: An \\ integrative literature review \\ Resistencia a los antimicrobianos y su correlación estadística con el consumo en hospitales: Una \\ revisión integrativa de la literatura
}

Recebido: 30/11/2021 | Revisado: 09/12/2021 | Aceito: 13/01/2022 | Publicado: 15/01/2022

Paulo Monteiro Araujo

ORCID: https://orcid.org/0000-0002-5829-6268 Universidade Federal do Piauí, Brasil E-mail: paulomonteirothe@gmail.com

Carina da Costa Braúna

ORCID: https://orcid.org/0000-0002-3815-6452 Universidade Federal do Piauí, Brasil

E-mail: carinabrauna@ hotmail.com

Susan Catherine Lima Lemos

ORCID: https://orcid.org/0000-0002-0090-1234 Universidade Federal do Piauí, Brasil E-mail: sucatherine2010@ gmail.com

Duanne Mendes Gomes

ORCID: https://orcid.org/0000-0003-1506-2055 Universidade Federal do Piauí, Brasil E-mail: duannemendesg@gmail.com Veridiana Rebelo dos Santos ORCID: https://orcid.org/0000-0002-1118-5392 Universidade Federal do Piauí, Brasil E-mail: veridianarebelo@gmail.com

Sávio Freire da Silva

ORCID: https://orcid.org/0000-0002-6221-6910 Universidade Federal do Piauí, Brasil E-mail: saviofreire.silva@gmail.com

Luciano da Silva Lopes

ORCID: https://orcid.org/0000-0002-7702-7258 Universidade Federal do Piaú, Brasil E-mail: lucianofarmaco@ufpi.edu.br

\section{Resumo}

Esta revisão integrativa teve por objetivo determinar quais são as principais bactérias que possuem correlações positivas entre o aumento do consumo de antimicrobianos e o aumento da resistência bacteriana em âmbito hospitalar. Resumiram-se os artigos, através de revisão integrativa, encontrados nas bases Pubmed ${ }^{\circledR}$ e Embase ${ }^{\circledR}$, utilizando as seguintes estratégias de busca: (("Microbial Sensitivity Tests"[Mesh]) AND "Hospitals"[Mesh]) AND "Drug Utilization"[Mesh] e 'drug utilization'exp AND 'hospital'exp AND 'antibiotic sensitivity'exp, respectivamente. Sintetizando o autor, ano de publicação, local de estudo, população estudada, metodologia de avaliação do consumo e da relação estatística e as correlações positivas encontradas entre as espécies ou gêneros bacterianos associados com os dados de consumo de uma determinada classe de antimicrobianos. As estratégias de busca encontraram no total 414 artigos, sendo que após a aplicação dos critérios de inclusão restaram 10 artigos que atendiam a todos os critérios utilizados. As principais bactérias ou gêneros bacterianos envolvidos com correlações positivas foram $P$. aeruginosa (42,6\%), E. coli $(24,1 \%)$ e Acinetobacter spp. (9,3\%). A maioria das correlações positivas encontradas foram relacionadas a mesma classe, todavia cerca de $48,2 \%$ foram cruzadas. Destacaram-se a $P$. aeruginosa, E. coli e o gênero Acinetobacter spp., como as bactérias com maiores quantidade de correlações positivas. Bancos de dados internacionais como o GLASS, podem fortalecer a evidência estatística dessa relação, permitindo amostras maiores e mais diversas, contudo eles dependem de cooperação internacional. Esse trabalho pode amparar a farmacovigilância em hospitais destacando correlações já elucidadas, ao qual podem contribuir na otimização dos recursos.

Palavras-chave: Testes de sensibilidade microbiana; Uso racional de medicamentos; Estudos de correlação; Resistência bacteriana a antibióticos. 


\begin{abstract}
This integrative review aimed to determine which are the main bacteria that have positive correlations between the increase in antimicrobial consumption and the increase in bacterial resistance in hospitals. The articles were summarized through an integrative review, found in Pubmed ${ }^{\circledR}$ and Embase ${ }^{\circledR}$, using the following search strategies: ("Microbial Sensitivity Tests"[Mesh]) AND "Hospitals"[Mesh]) AND "Drug Utilization "[Mesh] and 'drug utilization'exp AND 'hospital'exp AND 'antibiotic sensitivity'exp, respectively. Summarizing the author, year of publication, place of study, population studied, consumption assessment methodology and the statistical relationship and the positive correlations found between bacterial species or genera associated with the consumption data of a particular class of antimicrobials. The search strategies found a total of 414 articles, and after applying the inclusion criteria, there were 10 articles that met all the criteria used. The main bacteria or bacterial genera involved with positive correlations were $P$. aeruginosa (42.6\%), E. coli (24.1\%) and Acinetobacter spp. (9.3\%). Since most of the positive correlations found were related to the same class, however about $48.2 \%$ were crossed. P. aeruginosa, E. coli and the genus Acinetobacter spp. stood out as the bacteria with the highest amount of positive correlations. International databases such as GLASS, can strengthen the statistical evidence of this relationship, allowing larger and more diverse samples, however they depend on international cooperation. This work can support pharmacovigilance in hospitals highlighting correlations already elucidated, thus contributing to the optimization of resources.
\end{abstract}

Keywords: Microbial sensitivity tests; Drug utilization; Correlation of data; Antibacterial drug resistance.

\title{
Resumen
}

Esta revisión integradora tuvo como objetivo determinar cuáles son las principales bacterias que tienen correlaciones positivas entre el aumento del consumo de antimicrobianos y el aumento de la resistencia bacteriana en los hospitales. Los artículos fueron resumidos a través de una revisión integradora, encontrada en Pubmed ${ }^{\circledR}$ y Embase ${ }^{\circledR}$, utilizando las siguientes estrategias de búsqueda: ("Microbial Sensitivity Tests"[Mesh]) AND "Hospitals"[Mesh]) AND "Drug Utilization"[Mesh] and 'utilización de fármacos'exp Y 'hospital'exp Y 'sensibilidad a antibióticos'exp, respectivamente. Resumiendo el autor, año de publicación, lugar de estudio, población estudiada, metodología de evaluación del consumo y la relación estadística y las correlaciones positivas encontradas entre especies o géneros bacterianos asociados a los datos de consumo de una clase particular de antimicrobianos. Las estrategias de búsqueda encontraron un total de 414 artículos, y después de aplicar los criterios de inclusión, hubo 10 artículos que cumplieron con todos los criterios utilizados. Las principales bacterias o géneros bacterianos involucrados con correlaciones positivas fueron $P$. aeruginosa (42,6\%), E. coli (24,1\%) y Acinetobacter spp. (9,3\%). La mayoría de las correlaciones positivas encontradas estaban relacionadas con la misma clase, sin embargo, alrededor del 48,2\% fueron cruzadas. P. aeruginosa, E. coli y el género Acinetobacter spp., se destacaron como las bacterias con mayor cantidad de correlaciones positivas. Las bases de datos internacionales como GLASS pueden fortalecer la evidencia estadística de esta relación, permitiendo muestras más grandes y diversas, sin embargo, dependen de la cooperación internacional. Este trabajo puede apoyar la farmacovigilancia en hospitales destacando correlaciones ya dilucidadas, que pueden contribuir a la optimización de recursos.

Palabras clave: Pruebas de sensibilidad microbiana; Utilización de medicamentos; Estudios de correlación; Farmacorresistencia bacteriana.

\section{Introdução}

A resistência microbiana tem se tornado um problema global com maiores consequências a cada ano e com o aumento desses índices, há o aumento dos custos e a piora do prognóstico de pacientes atendidos em instituições de saúde ou em âmbito domiciliar (Chandy et al., 2014). Além disso, o aumento do uso desses medicamentos é um fator intrinsecamente ligado a redução da sensibilidade a antimicrobianos de diversas bactérias (Levy \& Marshall, 2004). Revisões sistemáticas têm mostrado associação significativa entre uso prévio de antimicrobianos e o isolamento de bactéria gram-negativas multirresistentes a antimicrobianos (MacAdam et al., 2006).

O monitoramento do uso de antimicrobianos tem se mostrado com parte essencial para a caracterização da relação entre o consumo desses medicamentos e as variações nos perfis de sensibilidade bacterianos. Numa metanálise de 243 artigos, foi observado que em países do sul da Europa existe uma forte correlação entre o consumo de agentes antimicrobianos e a resistência bacteriana em comparação a outras áreas avaliadas. Vale ressaltar que o aumento da resistência não afeta apenas o indivíduo, mas também pode ter consequências em sua comunidade, país ou região (Bell et al., 2014). 
Assim, otimizar o uso dos antimicrobianos é essencial para a segurança do paciente e de sua comunidade. Programas que visem a promoção do uso racional de antimicrobianos têm gerado evidências cada vez mais sólidas quanto a sua importância (Davey et al., 2017).

Em janeiro de 2013, o Fórum Econômico Mundial (FEM) destacou que a resistência bacteriana é um dos maiores riscos para a segurança global (WEF, 2013). Há muitos anos enfatiza-se a necessidade de um sistema maior que permita maior definição da relação entre o consumo de agentes antimicrobianos e o aumento da resistência bacteriana (Hanberger et al., 2001). No entanto, de acordo com a Organização Mundial da Saúde (OMS), não existia uma estratégia de vigilância coordenada para o monitoramento de bactérias resistentes a antimicrobianos (WHO, 2014).

Isso muda em 2015 com o início do Global Antimicrobial Resistance and Use Surveillance System (GLASS). Sendo que em 2020 foi introduzido o modulo Antimicrobial Consumption Module (AMC), o qual tem por objetivo incluir dados de consumo ao projeto inicial do GLASS, permitindo melhor elucidação do fenômeno da resistência e do uso de antimicrobianos, com dados em escala global (WHO, 2021b). Todavia, países de baixa renda ou renda média baixa têm menor taxa de adesão a esse sistema, representando um entrave para um sistema global de vigilância (WHO, 2020).

Considerando o cenário descrito, esta revisão integrativa teve por objetivo determinar quais são as principais bactérias que possuem correlações positivas entre o aumento do consumo de antimicrobianos e o aumento da resistência bacteriana em âmbito hospitalar.

\section{Metodologia}

Trata-se de uma revisão integrativa que buscou artigos em duas bases: PubMed $^{\circledR}$ e a Embase ${ }^{\circledR}$, visando sintetizar quais são as principais bactérias que possuem correlações positivas entre o aumento do consumo de antimicrobianos e o aumento da resistência bacteriana em âmbito hospitalar.

\subsection{Fase de identificação}

Utilizou-se o sistema de metadados de cada uma das bases a fim de tornar a pesquisa a mais ampla possível: Medical Subject Headings (MeSH) para o PubMed ${ }^{\circledR}$ e o Embase subject headings (Entree) para a Embase ${ }^{\circledR}$. As palavras foram escolhidas por sua relação com o tema, tendo como objetivo a otimização da seleção de artigos relacionados com o mesmo. As estratégias foram delineadas de forma a manter a maior similaridade possível, logo, apesar das palavras-chave não serem as mesmas, todas são consideradas sinônimos em suas respectivas bases.

\subsubsection{Pubmed $^{\circledR}(\mathrm{MeSH})$}

Realizou-se a pesquisa na base em 04 de janeiro de 2020 utilizando a seguinte estratégia de busca: (("Microbial Sensitivity Tests"[Mesh]) AND "Hospitals"[Mesh]) AND "Drug Utilization"[Mesh]. Consideraram-se também todas as palavras sinônimas e que estavam abaixo hierarquicamente na subdivisão do MeSH. Foram então selecionados para a próxima etapa, todos os artigos encontrados por essa estratégia de busca, com o limite temporal até o ano de 2020.

\subsubsection{Embase ${ }^{\circledR}$ (Emtree)}

Realizou-se a pesquisa na literatura em 16 de março de 2020 utilizando a seguinte estratégia de busca: 'drug utilization'exp AND 'hospital'exp AND 'antibiotic sensitivity'exp. Consideraram-se também todas as palavras sinônimas hierarquicamente abaixo na subdivisão do Emtree, incluindo para a próxima etapa todos os artigos encontrados até o ano de 2020. 


\subsection{Fase de seleção}

Avaliou-se o título e o resumo dos artigos, a fim de determinar se eles tratavam de alguma forma a correlação estatística entre o consumo de antimicrobianos e a resistência bacteriana em ambiente hospitalar, como também se o artigo era encontrado em inglês, caso eles não se enquadrassem nesses critérios eram excluídos.

\subsection{Fase de Elegibilidade}

Nesta fase foi avaliado o texto do artigo de forma completa. Foram excluídos os artigos que não eram encontrados na íntegra nos repositórios científicos disponíveis, que não avaliavam mais de 3 classes antimicrobianas (preferiu-se definir uma quantidade mínima de classes, pois acredita-se que assim o estudo representaria de forma mais completa a realidade do ambiente hospitalar). Retiraram-se, também, artigos que possuíam dados diferentes do âmbito hospitalar, sem que se pudessem estratificar somente os dados referentes ao ambiente de estudo. Por fim, somente foram inclusos os artigos que possuíam correlações positivas (aumento do consumo relacionado ao aumento da resistência observada), considerando correlações positivas aquelas que possuíam $\mathrm{p}<0,05$.

\subsection{Fase de inclusão}

Ao fim da estratégia de busca foram incluídos 10 artigos que eram adequados ao objetivo proposto desta síntese (Figura 1).

Figura 1 - Fluxo da seleção de artigos utilizados na revisão.

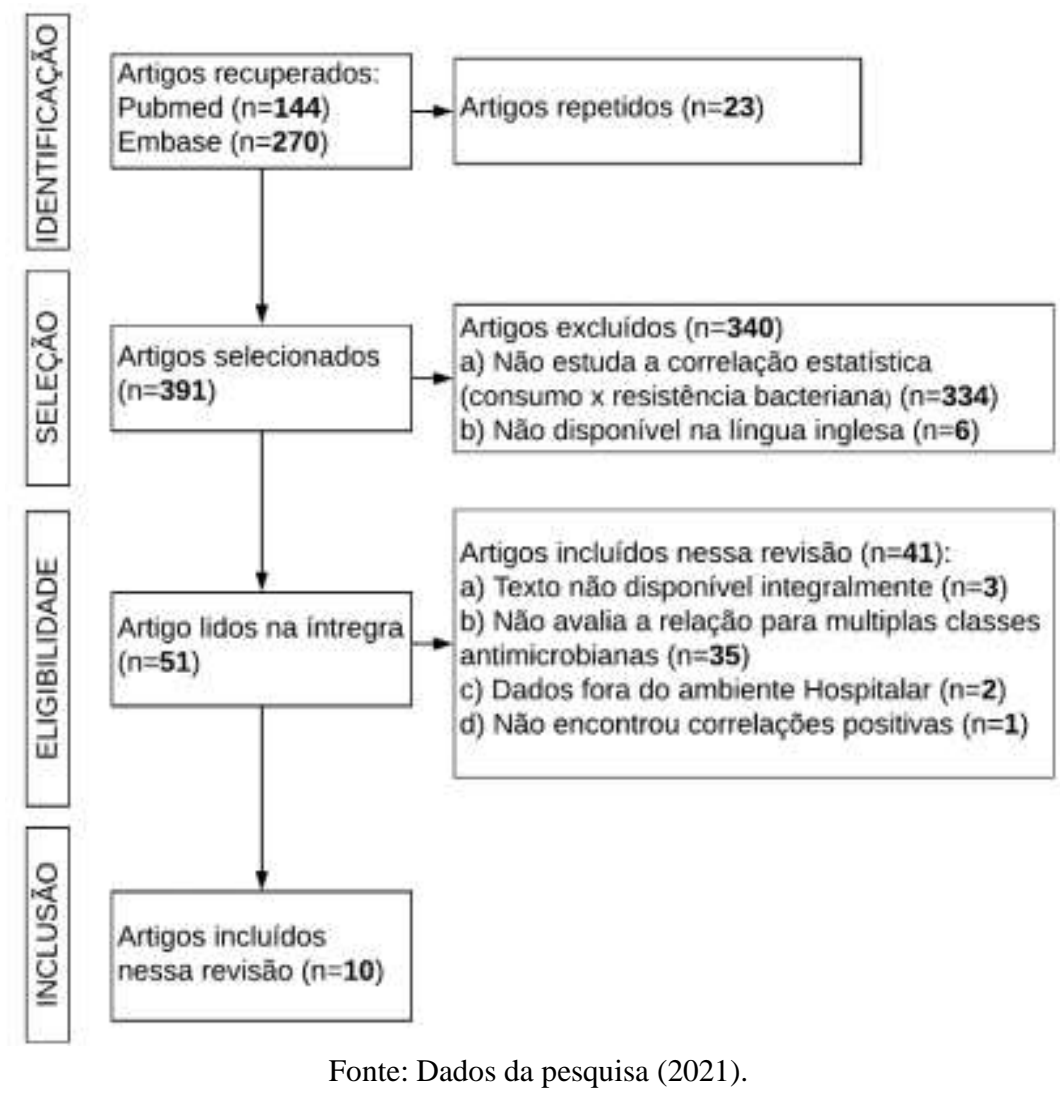

\subsection{Extração e síntese dos dados}

Os investigadores, primariamente, extraíram dos artigos os seguintes dados: autor, ano de publicação, local de estudo, população estudada, metodologia de avaliação do consumo e da relação estatística. Em seguida, eles extraíram as correlações 
positivas encontradas entre as espécies ou gêneros bacterianos associados com os dados de consumo de um determinado antimicrobiano ou classe, sintetizando as principais bactérias estudadas, a quantidade de correlações positivas e se a correlação encontrada era de resistência cruzada ou não. As classes de antimicrobianos foram estratificadas com a ajuda do Anatomical Therapeutic Chemical Code (ATC) (WHO, 2021a), sendo considerado o nível superior mais próximo para classificação.

\section{Resultados e Discussão}

Na fase de identificação 414 artigos (144 Pubmed ${ }^{\circledR}$ e 270 Embase $^{\circledR}$ ) foram recuperados, todavia 23 deles eram comuns a ambas as bases. Após a exclusão destes, 391 artigos passaram a próxima fase (Figura 1). Na fase de seleção 334 artigos foram excluídos por não avaliar a relação estatística entre o consumo e a resistência bacteriana e 6 artigos foram excluídos por estarem em outra língua que não o inglês, restando assim 51 artigos para a leitura na íntegra (Figura 1).

$\mathrm{Na}$ avaliação de elegibilidade dos artigos, fase na qual existia leitura integral do texto, 3 artigos não foram lidos na íntegra, pois não foram encontrados em sua forma completa, sendo assim excluídos; outros 2 artigos foram retirados por possuírem dados ambulatoriais em suas correlações sem que fosse possível isolar os dados referentes somente ao âmbito hospitalar; 35 não avaliavam a relação para mais de 3 classes de antimicrobianos - a exclusão de artigos que avaliavam menos de 3 classes de antimicrobianos deu-se pela menor representatividade da realidade encontrada em âmbito hospitalar. Um artigo com metodologia adequada ao objetivo não evidenciou correlações positivas entre o consumo e a resistência microbiana (Eagye \& Nicolau, 2011).

De acordo com o Índice de Desenvolvimento Humano (IDH) (UNDP, 2018) de 2018, 40\% dos artigos encontrados foram realizados em países subdesenvolvidos, sendo representados nesse grupo 3 artigos da China e 1 do Brasil. Destaca-se que ambos os países, mesmo que classificados como subdesenvolvidos, encontram-se no grupo de países de renda média alta (tabela 1) (The World Bank, 2021).

Para os países desenvolvidos, foram recuperados artigos advindos das seguintes nações: Croácia 1, Espanha 1, Japão 1, Singapura 1, Suécia 1 e Suíça 1. Os artigos que mais conseguiram recuperar correlações positivas foram dos autores: Hsu, et al. (2010), Loeffler, et al. (2003) e Muraki, et al. (2013). A maioria dos artigos era limitada a poucos hospitais com exceção do estudo de Muraki, et al. (2013), o qual avaliou dados de 203 hospitais japoneses. Todas as correlações positivas encontradas estão representadas na Tabela 1.

A Dose Diária Definida (DDD) foi a medida de consumo utilizada nos artigos avaliados, sendo dividida por PacientesDia (PD) ou Admissões-Dia (AD). Essas outras duas medidas visam a homogeneização de hospitais ou conjunto de hospitais de diferentes portes (Wertheimer, 1986). Nota-se um uso amplo de regressões como forma estatística de avaliação do consumo, sendo aplicado ou não o lag conforme os critérios dos autores.

Esses métodos de regressão linear permitem a comparação de duas variáveis que podem apresentar relação matemática entre si. Esse tipo de metodologia tem sido amplamente utilizado em diversos tipos de estudos e permitem a comparação entre variáveis dicotômicas ou contínuas (Hayes \& Montoya, 2017). Porém, o uso de técnicas temporais como o Autoregressive Integrated Moving Average (ARIMA), permite avaliar as relações de variáveis que podem ocorrer com certo atraso, avaliando a relação do modelo no futuro ou no passado. No entanto, esta análise isolada pode levar a valores de p não confiáveis, um problema que pode ser superado com técnicas auxiliares (Jiang et al., 2018). Ambas as técnicas foram utilizadas nos artigos estudados, entretanto houve dificuldade de enumeração de todos os testes realizados. 
Tabela 1 - Características dos estudos e correlações positivas encontradas.

\begin{tabular}{|c|c|c|c|}
\hline Autor (Ano) & $\begin{array}{l}\text { Local do estudo } \\
\text { (Bactérias estudadas) }\end{array}$ & $\begin{array}{l}\text { Metodologia de } \\
\text { avaliação do consumo e } \\
\text { de relação estatística }\end{array}$ & Correlações positivas do consumo e resistência \\
\hline $\begin{array}{l}\text { (Guo et al., } \\
2015 \text { ) }\end{array}$ & $\begin{array}{l}\text { Shanghai Hospital-China }(E . \\
\text { coli, } K . \quad \text { pneumoniae, } P . \\
\text { aeruginosa e A. baumannii) }\end{array}$ & $\begin{array}{l}\text { DDD/1000 PDs } \\
\text { Regressão (ARIMA) }\end{array}$ & $\begin{array}{l}\text { P. aeruginosa } \\
1 \text { J01MA-Fluoroquinolones } x \text { J01MA-Fluoroquinolones; } \\
2 \text { J01DD - Third-generation cephalosporins } x \text { J01DD - } \\
\text { Third-generation cephalosporins }\end{array}$ \\
\hline $\begin{array}{l}\text { (Zou et al., } \\
2015)\end{array}$ & $\begin{array}{l}\text { The First Affiliated Hospital - } \\
\text { Xi'an Jiaotong University - } \\
\text { China (E. coli, A. baumannii, } \\
\text { S. aureus, P. aeruginosa e } \\
\text { K. pneumoniae) }\end{array}$ & $\begin{array}{l}\text { DDD/100 PDs } \\
\text { Regressão (ARIMA) }\end{array}$ & $\begin{array}{l}\text { P. aeruginosa } \\
1 \mathrm{~J} 01 \mathrm{DH}-\text { Carbapenems } x \mathrm{~J} 01 \mathrm{DH}-\text { Carbapenems; } \\
2 \mathrm{~J} 01 \mathrm{DD}-\text { Third-generation cephalosporins } x \mathrm{~J} 01 \mathrm{DH}- \\
\text { Carbapenems } \\
\text { K. pneumoniae } \\
1 \mathrm{~J} 01 \mathrm{~GB}-\text { Other aminoglycosides } x \mathrm{~J} 01 G B-\text { Other } \\
\text { aminoglycosides }\end{array}$ \\
\hline $\begin{array}{l}(\mathrm{Xu} \text { et al., } \\
2013)\end{array}$ & $\begin{array}{l}\text { Um hospital terciário - China } \\
\text { (A. baumannii) }\end{array}$ & $\begin{array}{l}\text { DDD/1000 PDs - } \\
\text { Regressão (análise de } \\
\text { séries temporais com } \\
\text { aplicação de lag) }\end{array}$ & $\begin{array}{l}\text { A. baumannii } \\
1 \mathrm{~J} 01 \mathrm{DH}-\text { Carbapenems } x \mathrm{~J} 01 \mathrm{DH}-\text { Carbapenems }\end{array}$ \\
\hline $\begin{array}{l}\text { (Sousa et al., } \\
2013 \text { ) }\end{array}$ & $\begin{array}{l}\text { Hospital A Coruña - Espanha } \\
\text { (P. aeruginosa e } \\
\text { A. baumannii) }\end{array}$ & $\begin{array}{l}\text { DDD/100 PDs - } \\
\text { Regressão (linear) }\end{array}$ & $\begin{array}{l}\text { P. aeruginosa } \\
1 \text { J01DH - Carbapenems } x J 01 D H-\text { Carbapenems; } \\
2 \text { J01MA-Fluoroquinolones } x \text { J01DH - Carbapenems } \\
\text { A. baumannii } \\
1 \text { J01GB - Other aminoglycosides } x \text { J01DH-Carbapenems }\end{array}$ \\
\hline $\begin{array}{l}\text { (Muraki et al., } \\
\text { 2013) }\end{array}$ & $\begin{array}{l}203 \text { Hospitais Japoneses - } \\
\text { Japão }(P . \text { aeruginosa })\end{array}$ & $\begin{array}{l}\text { DDD/1000 PDs } \\
\text { Regressão (linear) }\end{array}$ & 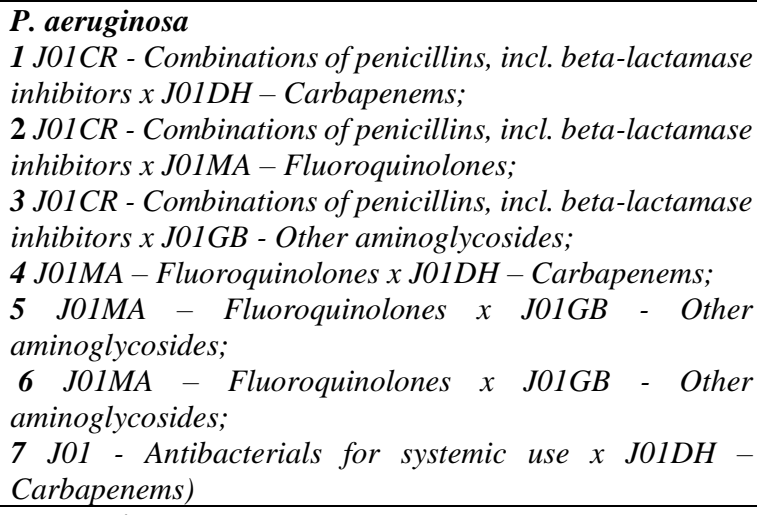 \\
\hline $\begin{array}{l}\text { (Erdeljić et al., } \\
\text { 2011) }\end{array}$ & $\begin{array}{l}\text { University Hospital Zagreb- } \\
\text { Croácia }(P . \text { aeruginosa })\end{array}$ & $\begin{array}{l}\text { DDD/1000 ADs - } \\
\text { Regressão (linear e } \\
\text { análise de séries } \\
\text { temporais com aplicação } \\
\text { de lag) }\end{array}$ & $\begin{array}{l}\text { P. aeruginosa } \\
1 \text { J01DH-Carbapenems } x \text { J01DH -Carbapenems; } \\
2 \text { J01MA-Fluoroquinolones } x \text { J01MA-Fluoroquinolones; } \\
3 \text { J01DE - Fourth-generation cephalosporins } x \text { JO1DE - } \\
\text { Fourth-generation cephalosporins }\end{array}$ \\
\hline $\begin{array}{l}\text { (Hsu et al., } \\
2010)\end{array}$ & $\begin{array}{l}\text { Quatro hospitais público de } \\
\text { Singapura }- \text { Singapura }(E . \\
\text { coli, K. pneumoniae, } P \text {. } \\
\text { aeruginosa } \\
\text { spp.) }\end{array}$ & $\begin{array}{l}\text { DDD/1000 PDs - } \\
\text { Regressão (Linear e } \\
\text { relação cruzada com } \\
\text { aplicação de } l a g \text { ) }\end{array}$ & 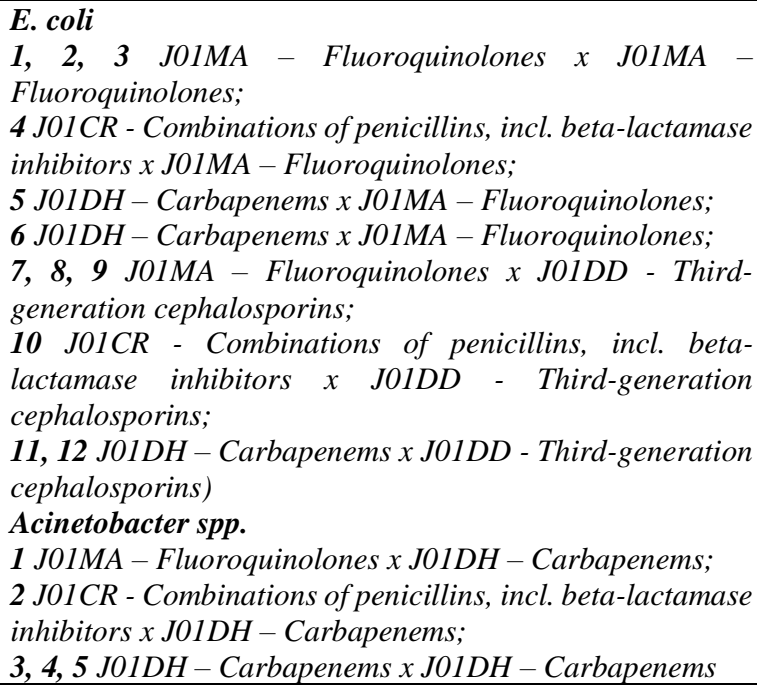 \\
\hline $\begin{array}{l}\text { (Jacoby et al., } \\
2010)\end{array}$ & $\begin{array}{l}\text { Hospital de Clínicas } \\
\text { de Porto Alegre-Brasil } \\
\text { (Klebsiella spp., E. coli, } \\
\text { Pseudomonas } \\
\text { spp., }\end{array}$ & $\begin{array}{l}\text { DDD/100 } \\
\text { Regressão } \\
\text { logística) }\end{array}$ & $\begin{array}{l}\text { Klebsiella ssp. } \\
1 \text { J01MA - Fluoroquinolones } x \text { JO1DD - Third-generation } \\
\text { cephalosporins; } \\
2 \text { J01D - Other beta-lactam antibacterials x JO1DD - Third- } \\
\text { generation cephalosporins }\end{array}$ \\
\hline
\end{tabular}




\begin{tabular}{|c|c|c|c|c|}
\hline & $\begin{array}{l}\text { Acinetobacter } \\
\text { Enterobacter spp., } \\
\text { Citrobacter spp., } \\
\text { spp., Proteus spp. } \\
\text { S. maltophilia, B. } \\
\text { Enterococcus spp., S. aureus) } \\
\end{array}$ & & & $\begin{array}{l}\text { Pseudomonas spp. } \\
1 \text { J01D - Other beta-lactam antibacterials x J01DD - Third- } \\
\text { generation cephalosporins }\end{array}$ \\
\hline $\begin{array}{l}\text { (Loeffler et al., } \\
\text { 2003) }\end{array}$ & $\begin{array}{l}\text { Hospital Cantonal de Genève } \\
\text { - Suíça (E. coli, Klebsiella } \\
\text { spp., P. aeruginosa, H. } \\
\text { influenzae, } \\
\begin{array}{l}\text { S. aureus, coagulase-negative } \\
\text { staphylococci (CNS) e S. } \\
\text { pneumoniae) }\end{array}\end{array}$ & $\begin{array}{l}\text { DDD/1000 PDs } \\
\text { Regressão (linear) }\end{array}$ & & $\begin{array}{l}\text { E. coli } \\
1 \text { J01CA - Penicillins with extended spectrum x J01CA - } \\
\text { Penicillins with extended spectrum } \\
\text { P. aeruginosa } \\
1 \text { J01CA - Penicillins with extended spectrum x J01CA - } \\
\text { Penicillins with extended spectrum; } \\
2 \text { J01CR - Combinations of penicillins, incl. beta-lactamase } \\
\text { inhibitors x J01CA - Penicillins with extended spectrum; } \\
\text { 3 J01D - Other beta-lactam antibacterials x J01DD - Third- } \\
\text { generation cephalosporins; } \\
\text { 4, } 5 \text {, } 6 \text { J01GB - Other aminoglycosides x J01GB - Other } \\
\text { aminoglycosides; } \\
7 \text { J01D - Other beta-lactam antibacterials x JO1DB - First- } \\
\text { generation cephalosporins) } \\
\text { Coagulase-negative Staphylococci } \\
1,2 \text { J01GB - Other aminoglycosides x J01GB - Other } \\
\text { aminoglycosides } \\
\text { S. pneumoniae } \\
1 \text { J01CE - Beta-lactamase sensitive penicillins x J01CE - } \\
\text { Beta-lactamase sensitive penicillins }\end{array}$ \\
\hline $\begin{array}{l}\text { (Monsen et al., } \\
1999 \text { ) }\end{array}$ & $\begin{array}{l}3 \text { hospitais do condado } \\
\text { Västerbotten - Suécia } \\
\text { (Staphylococci spp.) }\end{array}$ & $\begin{array}{l}\text { DDD/1000 } \quad \text { PDs } \\
\text { Regressão (logística) }\end{array}$ & - & $\begin{array}{l}\text { S. epidermidis } \\
1 \mathrm{~J} 01 \mathrm{MA}-\text { Fluoroquinolones } x \mathrm{~J} 01 \mathrm{MA}-\text { Fluoroquinolones; } \\
2 \mathrm{~J} 01 \mathrm{EE} \text {-Combinations of sulfonamides and trimethoprim, } \\
\text { incl. Derivatives x J01EE - Combinations of sulfonamides } \\
\text { and trimethoprim, incl. Derivatives; } \\
3 \mathrm{~J} 01 \mathrm{CF} \text { - Beta-lactamase resistant penicillins x J01CF - } \\
\text { Beta-lactamase resistant penicillins; } \\
4 \mathrm{~J} 01 \text { - Antibacterials for systemic use x J01-Antibacterials } \\
\text { for systemic use) }\end{array}$ \\
\hline
\end{tabular}

Legenda: Autoregressive Integrated Moving Average (ARIMA), Pacientes-dia (PD), Admissão-dia (AD). Fonte: Dados da pesquisa (2021).

As bactérias ou gêneros bacterianos com maior número de correlações positivas encontradas foram P. aeruginosa 23 (42,6\%), E. coli $13(24,1 \%)$ e Acinetobacter spp. 5 (9,3\%). Destas, 28 (51,8\%) estavam relacionadas ao consumo de uma determinada classe de antimicrobianos e o aumento da resistência a ela, todavia $26(48,2 \%)$ eram correlações cruzadas, fato que ocorre quando o aumento do consumo de determinada classe de antimicrobianos relaciona-se com o aumento de resistência a outra classe de antimicrobianos (Tabela 2).

Tabela 2 - Resumo das correlações positivas encontradas.

\begin{tabular}{lc}
\hline Correlações positivas encontradas por bactéria ou gênero bacteriano & $\mathbf{N}(\%)$ \\
$P$. aeruginosa & $23(42,6 \%)$ \\
E. coli & $13(24,1 \%)$ \\
Acinetobacter spp. & $5(9,3 \%)$ \\
Outros & $10(18,5 \%)$ \\
Correlações positivas de consumo e resistência & $\mathbf{N}(\%)$ \\
Mesma classe & $28(51,8 \%)$ \\
Resistencia cruzada & $26(48,2 \%)$ \\
Classes de antimicrobianos das correlações positivas & $\mathbf{N}(\%)$ \\
J01MA - Fluoroquinolones & $15(27,8 \%)$ \\
J01DH - Carbapenems & $11(20,4 \%)$ \\
J01GB - Other aminoglycosides & $7(13 \%)$ \\
J01CR - Combinations of penicillins, incl. beta-lactamase inhibitors & $7(13 \%)$ \\
Outros & $14(25,8 \%)$ \\
\hline
\end{tabular}


$\mathrm{O}$ aumento da resistência pelo aumento do consumo de antimicrobianos mata milhares de pessoas por infeções adquiridas em hospitais, muitas das quais são causadas por bactérias multirresistentes. Essa situação é promovida em parte pelo abuso do uso de antimicrobianos e a inabilidade de controlar a disseminação das bactérias e seus genes de resistência. Programas de stewardship podem contribuir na diminuição dos custos relacionados aos antimicrobianos, sejam eles diretos ou indiretos (Dellit et al., 2007).

A cada dia torna-se mais clara a relação entre o consumo de antimicrobianos e a resistência. Em um estudo de coorte prospectivo multicêntrico que estudou a taxa da aquisição do fenótipo de multirresistência bacteriana em pacientes que não eram previamente colonizados com esse tipo de bactérias, observou-se a incidência para cada 1000 dias de terapia com antimicrobianos de: 14 para carbapenêmicos, 9 para glicopeptídeos e 6 para cefalosporinas de amplo espectro e quinolonas. As maiores taxas de aquisição observadas foram de pacientes dialíticos ou diabéticos, e quatro variáveis foram associadas independentemente a aquisição da multirresistência: uso de carbapenêmicos, idade acima de 70 anos, período de internação maior que 16 dias e infecção pelo vírus da imunodeficiência humana (Tacconelli et al., 2009).

Existe uma ausência de um banco de dados sobre a resistência bacteriana e o consumo de antimicrobianos, principalmente em países de baixa renda. Antimicrobianos devem ter seu uso complementado por ferramentas adequadas para o diagnóstico clínico que melhor determinem a suscetibilidade dos patógenos aos antimicrobianos utilizados na instituição. A aplicabilidade e acessibilidade dessas ferramentas deve sempre ser considerada em países de baixa renda e renda média baixa, os quais possuem seu orçamento como limitante, desde a aquisição de medicamentos, a implementação de novas ferramentas diagnósticas e de acompanhamento (WHO, 2015).

Os países mais ricos devem contribuir na melhoria dessa vigilância, pois a resistência bacteriana a cada dia representa um desafio maior para a sociedade como um todo. Há iniciativas internacionais que começam a trabalhar para a melhoria da vigilância em países subdesenvolvidos (Fleming Fund, 2021). Todavia, os dados advindos deles ainda são limitados (WHO, 2020). Na amostra de artigos avaliados somente foram encontrados trabalhos de países de renda média alta ou de renda alta ponto que poderá ser melhorado com a implementação completa do GLASS (WHO, 2021b).

A maioria das bactérias avaliadas pertenciam ao acrônimo ESKAPE (Enterococcus faecium, Staphylococcus aureus, Klebsiella pneumoniae, Acinetobacter baumannii, Pseudomonas aeruginosa e Enterobacter spp.), bactérias que podem escapar dos efeitos dos antimicrobianos comumente usados pelo desenvolvimento de mecanismos de resistência (Pendleton et al., 2013).

A P. aeruginosa é conhecida por sua grande capacidade intrínseca de resistência a diversos agentes antimicrobianos, capacidade esta que é controlada pela expressão de diversos operons - conjunto de genes que confere certa característica a um organismo (Fukuda et al., 1990; Hirai et al., 1987). O consumo de fluoroquinolonas está associado ao desenvolvimento de fenótipos de resistência a esta bactéria, estando associado não só a resistências desta classe, mas também a outras que não necessariamente apresentam estruturas químicas similares ou que pertençam por exemplo à mesma classe (Falagas \& Kopterides, 2006; Miliani et al., 2011). Dentre os fatores que podem permitir essa adaptabilidade destacam-se a perda de proteínas de membrana, superexpressão de genes de efluxo ativo para múltiplas drogas, mudança na permeabilidade celular e produção de enzimas de clivagem ativas para antimicrobianos (Zou et al., 2015).

No artigo de Sousa e seus colaboradores (2013), com base em seus resultados, presumiu-se que a diminuição da resistência da $P$. aeruginosa pode ser parcialmente explicada pela diminuição do uso do imipeném e ciprofloxacina, pois ambos os agentes estavam associados às variações da densidade de resistência do imipeném. Indo além, ele sugere que incidência de $P$. aeruginosa resistente a carbapenêmicos pode ser reduzida pela diminuição do uso carbapenêmicos, ciprofloxacina, cefalosporinas de terceira geração, Piperacilina/Tazobactam e aminoglicosídeos.

Guo e seus colaboradores (2015) destacam que diversas associações significativas foram reveladas com o uso da correlação estatística. No entanto, após a filtragem que visava a retirada de correlações ilegítimas, diminui consideravelmente o 
número inicial de correlações encontradas. Nesse artigo também foi possível ressaltar que, após a remoção da pressão positiva desencadeada pelos antibióticos, observou-se a diminuição lenta do perfil de resistência. Um dos principais motivos atribuídos pelo artigo é que a resistência a antimicrobianos relaciona-se com as diferenças nas capacidades adaptativas de cada bactéria. Nem sempre a resistência a um antimicrobiano permite a melhor capacidade de sobrevivência em um ambiente sem a pressão de antimicrobianos: com o tempo a mesma retorna ao seu estado natural de equilíbrio, de acordo com o ambiente que se localiza.

Além disso, a E. coli tem destaque por possuir uma característica especial: ela é um dos maiores reservatórios e doadora de genes responsáveis pelo desenvolvimento de resistência em humanos e animais, provocando assim tratamentos falhos em ambos. Relacionando-se principalmente com a família Enterobacteriaceae, serve como doador principalmente por transferência horizontal de genes de resistência. Sendo assim, é considerada como uma das principais bactérias que representam um desafio aos sistemas mundiais de saúde, ainda mais quando se observa sua grande capacidade de promover surtos (Poirel et al., 2018).

Outro ponto interessante para E. coli, em um estudo que utilizou o ofloxacino, foi demonstrado: antimicrobianos que têm seu mecanismo baseado na modificação de alteração da capacidade de síntese de novas fitas de DNA podem induzir a formação de colônias multirresistentes a antimicrobianos, efeito esse que pode ocorrer após uma única exposição ao agente (Barrett et al., 2019). É um fator preocupante quando se avalia o envolvimento de fluoroquinolonas no desenvolvimento da resistência bacteriana.

Indo além, no estudo de Gallini e seus colaboradores (2010), foram reportados altos níveis do uso de fluoroquinolonas em sua comunidade, o que revelou uma influência significativa na resistência hospitalar da $E$. coli, provavelmente causada pela suscetibilidade dela em adquirir genes de resistência. A variação em cerca de 50\% dos níveis de resistência encontrada nesse trabalho vê se associada ao aumento considerável do consumo de fluoroquinolonas.

O comportamento de resistência da A. baumannii foi fortemente associado ao consumo de carbapenêmicos (Hsu et al., 2010; Sousa et al., 2013; Xu et al., 2013). O uso prévio de antimicrobianos, em especial o de carbapenêmicos, cefalosporinas de terceira geração e fluoroquinolonas - antimicrobianos de amplo espectro, também já foi associado como fator de risco para a resistência a imipeném (Kuo et al., 2012; Perez et al., 2007). Da mesma forma que o uso de carbapenêmicos e cefalosporinas de terceira geração parece ser relacionada com o desenvolvimento de A. baumannii resistente a múltiplas drogas (Falagas \& Kopterides, 2006).

O gênero Acinetobacter spp. pode exibir mecanismos de resistência a praticamente todas as classes de antimicrobianos existentes e possui uma grande capacidade de desenvolver novas formas de resistência. Seu sucesso em desencadear surtos devese a combinação de diversos fatores, dentre eles sua resistência ambiental e grande adaptabilidade. Geneticamente, ele pode possuir os mesmos transposões encontrados em outras espécies bacterianas como a Pseudomonas spp., Salmonella spp. e E. coli., além de diversos outros genes de resistência. As doenças desencadeadas por ele tendem a ocorrer em ambientes como o da Unidade de Terapia Intensiva, local em que a pressão antimicrobiana é extremamente presente (Perez et al., 2007).

A síntese dos artigos apresentou diversas dificuldades. Dentre os principais motivos, enfatiza-se que: (1) nem sempre era possível estratificar quais antimicrobianos estavam contidos na correlação estudada, (2) os microrganismos estudados nem sempre possuíam sua espécie especificada e (3) algumas correlações foram feitas com todo o arsenal disponível no hospital, mitigando a possibilidade de inferência para determinada classe. Além disso, a classificação ATC (WHO, 2021a) da OMS nem sempre possui uma boa resolução na distinção das classes como, por exemplo, as cefalosporinas que de forma geral que não possuem classificação própria, sendo classificadas conjuntamente com monobactâmicos, carbapenêmicos e penêmicos.

Do ponto de vista estatístico, outra dificuldade é revelada, pois as metodologias utilizadas para a avaliação da relação entre o consumo de antimicrobianos e a resistência bacteriana eram diversas, da mesma forma que não existia padronização na utilização de testes complementares ou o uso de lag (atraso na comparação entre os grupos a fim de emular o tempo de ação da pressão positiva que os antimicrobianos geram na flora bacterina do indivíduo), fator que poderia permitir a melhor 
caracterização desse fenômeno. Todavia, sua padronização deve ser um ponto a ser trabalhado pelas instituições que regem o bom uso de medicamentos como a OMS. O DDD, medida criada pela mesma, tem destaque como estratégia de avaliação de consumo de antimicrobianos nos artigos estudados, mostrando a força de uma metodologia embasada por uma grande instituição (WHO, 2019).

\section{Conclusão}

O fenômeno da resistência e sua associação com consumo de antimicrobianos é extremamente complexo. Os artigos avaliados abordaram a correlação entre a resistência e o consumo de antimicrobianos. Destacaram-se a P. aeruginosa, E. coli e o gênero Acinetobacter spp. como as bactérias ou gêneros bacterianos com maiores quantidade de correlações positivas. Sendo as fluoroquinolonas e os beta-lactâmicos de amplo espectro os antimicrobianos mais envolvidos com esse fenômeno. Essas bactérias devem receber enfoque em sua vigilância, pois a elucidação do fenômeno da resistência e o consumo parece bem claro. Ademais, nota-se que a resistência pode ser causada por via cruzada, fenômeno que ocorre quando o uso de um antimicrobiano de determinada classe gera o aumento da resistência a outro antimicrobiano de classe diferente.

Bancos de dados internacionais como o GLASS podem fortalecer a evidência estatística dessa relação, permitindo amostras maiores e mais diversas bem como melhor padronização da metodologia de análise, todavia eles dependem de cooperação internacional, a qual muitas vezes é deficitária. Esse trabalho pode amparar a farmacovigilância em hospitais destacando correlações já elucidadas, o que por sua vez pode contribuir na otimização dos recursos.

\section{Agradecimentos}

Este estudo foi realizado com o apoio da CAPES (Coordenação de Aperfeiçoamento de Pessoal de Nível Superior) e do PPGCF - UFPI (Programa de Pós-graduação em Ciências Farmacêuticas - Universidade Federal do Piauí).

\section{Referências}

Barrett, T. C., Mok, W. W. K., Murawski, A. M., \& Brynildsen, M. P. (2019). Enhanced antibiotic resistance development from fluoroquinolone persisters after a single exposure to antibiotic. Nature Communications, 10(1), 1177. https://doi.org/10.1038/s41467-019-09058-4

Bell, B. G., Schellevis, F., Stobberingh, E., Goossens, H., \& Pringle, M. (2014). A systematic review and meta-analysis of the effects of antibiotic consumption on antibiotic resistance. BMC Infectious Diseases, 14(1), 13. https://doi.org/10.1186/1471-2334-14-13

Chandy, S. J., Naik, G. S., Balaji, V., Jeyaseelan, V., Thomas, K., \& Lundborg, C. S. (2014). High cost burden and health consequences of antibiotic resistance: the price to pay. The Journal of Infection in Developing Countries, 8(09), 1096-1102. https://doi.org/10.3855/jidc.4745

Davey, P., Marwick, C. A., Scott, C. L., Charani, E., McNeil, K., Brown, E., Gould, I. M., Ramsay, C. R., \& Michie, S. (2017). Interventions to improve antibiotic prescribing practices for hospital inpatients. The Cochrane Database of Systematic Reviews, 2 , CD003543. https://doi.org/10.1002/14651858.CD003543.pub4

Dellit, T. H., Owens, R. C., McGowan, J. E., Gerding, D. N., Weinstein, R. A., Burke, J. P., Huskins, W. C., Paterson, D. L., Fishman, N. O., Carpenter, C. F., Brennan, P. J., Billeter, M., \& Hooton, T. M. (2007). Infectious Diseases Society of America and the Society for Healthcare Epidemiology of America Guidelines for Developing an Institutional Program to Enhance Antimicrobial Stewardship. Clinical Infectious Diseases, 44(2), 159-177. https://doi.org/10.1086/510393

Eagye, K. J., \& Nicolau, D. P. (2011). Change in antipseudomonal carbapenem susceptibility in 25 hospitals across 9 years is not associated with the use of ertapenem. Journal of Antimicrobial Chemotherapy, 66(6), 1392-1395. https://doi.org/10.1093/jac/dkr141

Erdeljić, V., Francetić, I., Bošnjak, Z., Budimir, A., Kalenić, S., Bielen, L., Makar-Aušperger, K., \& Likić, R. (2011). Distributed lags time series analysis versus linear correlation analysis (Pearson's $\mathrm{r}$ ) in identifying the relationship between antipseudomonal antibiotic consumption and the susceptibility of Pseudomonas aeruginosa isolates in a single Intensive Care Unit. International Journal of Antimicrobial Agents, 37(5), 467-471. https://doi.org/10.1016/j.ijantimicag.2010.11.030

Falagas, M. E., \& Kopterides, P. (2006). Risk factors for the isolation of multi-drug-resistant Acinetobacter baumannii and Pseudomonas aeruginosa: a systematic review of the literature. Journal of Hospital Infection, 64(1), 7-15. https://doi.org/10.1016/j.jhin.2006.04.015

Fleming Fund. (2021). Aims \& Values. 2021. https://www.flemingfund.org/about-us/our-aims/

Fukuda, H., Hosaka, M., Hirai, K., \& Iyobe, S. (1990). New norfloxacin resistance gene in Pseudomonas aeruginosa PAO. Antimicrobial Agents and Chemotherapy, 34(9), 1757-1761. https://doi.org/10.1128/AAC.34.9.1757 
Gallini, A., Degris, E., Desplas, M., Bourrel, R., Archambaud, M., Montastruc, J. L., Lapeyre-Mestre, M., \& Sommet, A. (2010). Influence of fluoroquinolone consumption in inpatients and outpatients on ciprofloxacin-resistant Escherichia coli in a university hospital. Journal of Antimicrobial Chemotherapy, 65(12), 2650-2657. https://doi.org/10.1093/jac/dkq351

Guo, W., He, Q., Wang, Z., Wei, M., Yang, Z., Du, Y., Wu, C., \& He, J. (2015). Influence of antimicrobial consumption on gram-negative bacteria in inpatients receiving antimicrobial resistance therapy from 2008-2013 at a tertiary hospital in Shanghai, China. American Journal of Infection Control, 43(4), 358-364. https://doi.org/10.1016/j.ajic.2014.12.010

Hanberger, H., Diekema, D., Fluit, A., Jones, R., Struelens, M., Spencer, R., \& Wolff, M. (2001). Surveillance of antibiotic resistance in European ICUs. Journal of Hospital Infection, 48(3), 161-176. https://doi.org/10.1053/jhin.2001.0987

Hayes, A. F., \& Montoya, A. K. (2017). A Tutorial on Testing, Visualizing, and Probing an Interaction Involving a Multicategorical Variable in Linear Regression Analysis. Communication Methods and Measures, 11(1), 1-30. https://doi.org/10.1080/19312458.2016.1271116

Hirai, K., Suzue, S., Irikura, T., Iyobe, S., \& Mitsuhashi, S. (1987). Mutations producing resistance to norfloxacin in Pseudomonas aeruginosa. Antimicrobial Agents and Chemotherapy, 31(4), 582-586. https://doi.org/10.1128/AAC.31.4.582

Hsu, L.-Y., Tan, T.-Y., Tam, V. H., Kwa, A., Fisher, D. A., \& Koh, T.-H. (2010). Surveillance and Correlation of Antibiotic Prescription and Resistance of Gram-Negative Bacteria in Singaporean Hospitals. Antimicrobial Agents and Chemotherapy, 54(3), 1173-1178. https://doi.org/10.1128/AAC.01076-09

Jacoby, T. S., Kuchenbecker, R. S., dos Santos, R. P., Magedanz, L., Guzatto, P., \& Moreira, L. B. (2010). Impact of hospital-wide infection rate, invasive procedures use and antimicrobial consumption on bacterial resistance inside an intensive care unit. Journal of Hospital Infection, 75(1), 23-27. https://doi.org/10.1016/j.jhin.2009.11.021

Jiang, X.-T., Ye, L., Ju, F., Wang, Y.-L., \& Zhang, T. (2018). Toward an Intensive Longitudinal Understanding of Activated Sludge Bacterial Assembly and Dynamics. Environmental Science \& Technology, 52(15), 8224-8232. https://doi.org/10.1021/acs.est.7b05579

Kuo, S.-C., Chang, S.-C., Wang, H.-Y., Lai, J.-F., Chen, P.-C., Shiau, Y.-R., Huang, I.-W., \& Lauderdale, T.-L. Y. (2012). Emergence of extensively drugresistant Acinetobacter baumannii complex over 10 years: Nationwide data from the Taiwan Surveillance of Antimicrobial Resistance (TSAR) program. BMC Infectious Diseases, 12(1), 200. https://doi.org/10.1186/1471-2334-12-200

Levy, S. B., \& Marshall, B. (2004). Antibacterial resistance worldwide: causes, challenges and responses. Nature Medicine, 10(S12), S122-S129. https://doi.org/10.1038/nm1145

Loeffler, J. M., Garbino, J., Lew, D., Harbarth, S., \& Rohner, P. (2003). Antibiotic Consumption, Bacterial Resistance and their Correlation in a Swiss University Hospital and its Adult Intensive Care Units. Scandinavian Journal of Infectious Diseases, 35(11-12), 843-850. https://doi.org/10.1080/00365540310016646

MacAdam, H., Zaoutis, T. E., Gasink, L. B., Bilker, W. B., \& Lautenbach, E. (2006). Investigating the association between antibiotic use and antibiotic resistance: impact of different methods of categorising prior antibiotic use. International Journal of Antimicrobial Agents, $28(4)$, 325-332. https://doi.org/10.1016/j.ijantimicag.2006.04.014

Miliani, K., L’Hériteau, F., Lacavé, L., Carbonne, A., \& Astagneau, P. (2011). Imipenem and ciprofloxacin consumption as factors associated with high incidence rates of resistant Pseudomonas aeruginosa in hospitals in northern France. Journal of Hospital Infection, 77(4), 343-347. https://doi.org/10.1016/j.jhin.2010.11.024

Monsen, T., Rönnmark, M., Olofsson, C., \& Wiström, J. (1999). Antibiotic susceptibility of staphylococci isolated in blood cultures in relation to antibiotic consumption in hospital wards. Scandinavian Journal of Infectious Diseases, 31(4), 399-404. https://doi.org/10.1080/00365549950163860

Muraki, Y., Kitamura, M., Maeda, Y., Kitahara, T., Mori, T., Ikeue, H., Tsugita, M., Tadano, K., Takada, K., Akamatsu, T., Yamada, T., Yamada, T., Shiraishi, T., \& Okuda, M. (2013). Nationwide surveillance of antimicrobial consumption and resistance to Pseudomonas aeruginosa isolates at 203 Japanese hospitals in 2010. Infection, 41(2), 415-423. https://doi.org/10.1007/s15010-013-0440-0

Pendleton, J. N., Gorman, S. P., \& Gilmore, B. F. (2013). Clinical relevance of the ESKAPE pathogens. Expert Review of Anti-Infective Therapy, 11(3), 297308. https://doi.org/10.1586/eri.13.12

Perez, F., Hujer, A. M., Hujer, K. M., Decker, B. K., Rather, P. N., \& Bonomo, R. A. (2007). Global Challenge of Multidrug-Resistant Acinetobacter baumannii. Antimicrobial Agents and Chemotherapy, 51(10), 3471-3484. https://doi.org/10.1128/AAC.01464-06

Poirel, L., Madec, J.-Y., Lupo, A., Schink, A.-K., Kieffer, N., Nordmann, P., \& Schwarz, S. (2018). Antimicrobial Resistance in Escherichia coli. Microbiology Spectrum, 6(4). https://doi.org/10.1128/microbiolspec.ARBA-0026-2017

Sousa, D., Castelo-Corral, L., Gutierrez-Urbon, J.-M., Molina, F., Lopez-Calvino, B., Bou, G., \& Llinares, P. (2013). Impact of ertapenem use on Pseudomonas aeruginosa and Acinetobacter baumannii imipenem susceptibility rates: collateral damage or positive effect on hospital ecology? Journal of Antimicrobial Chemotherapy, 68(8), 1917-1925. https://doi.org/10.1093/jac/dkt091

Tacconelli, E., De Angelis, G., Cataldo, M. A., Mantengoli, E., Spanu, T., Pan, A., Corti, G., Radice, A., Stolzuoli, L., Antinori, S., Paradisi, F., Carosi, G., Bernabei, R., Antonelli, M., Fadda, G., Rossolini, G. M., \& Cauda, R. (2009). Antibiotic usage and risk of colonization and infection with antibiotic-resistant bacteria: a hospital population-based study. Antimicrobial Agents and Chemotherapy, 53(10), 4264-4269. https://doi.org/10.1128/AAC.00431-09

The World Bank. (2021). DataBank. The World Bank. https://databank.worldbank.org/home.aspx

UNDP. (2018). Human Development Indices and Indicators. In United Nations Development Programme (UNDP).

WEF. (2013). Global Risks 2013: Eighth Edition. WHO. http://www3.weforum.org/docs/WEF_GlobalRisks_Report_2013.pdf 
Research, Society and Development, v. 11, n. 1, e55611124058, 2022

(CC BY 4.0) | ISSN 2525-3409 | DOI: http://dx.doi.org/10.33448/rsd-v11i1.24058

Wertheimer, A. I. (1986). The defined daily dose system (DDD) for drug utilization review. Hospital Pharmacy, 21(3), 258, 233-4, 239-41. http://europepmc.org/abstract/MED/10317694

WHO. (2014). Antimicrobial resistance: global report on surveillance 2014. In World Health Organization. https://apps.who.int/iris/handle/10665/112642

WHO. (2015). Global Action Alan: on Antimicrobial

https://apps.who.int/iris/bitstream/handle/10665/193736/9789241509763_eng.pdf?sequence=1

WHO. (2019). Definition and general considerations. World Health Organization. https://www.whocc.no/ddd/definition_and_general_considera/

WHO. (2020). GLASS Early Implementation Report: 2020. WHO. https://www.who.int/glass/resources/publications/early-implementation-report-2020/en/

WHO. (2021a). ATC/DDD Index 2021. World Health Organization. https://www.whocc.no/atc_ddd_index/WHO. (2021b). Global Antimicrobial Resistance Surveillance System (GLASS). WHO. https://www.who.int/glass/en/

Xu, J., Sun, Z., Li, Y., \& Zhou, Q. (2013). Surveillance and Correlation of Antibiotic Consumption and Resistance of Acinetobacter baumannii complex in a Tertiary Care Hospital in Northeast China, 2003-2011. International Journal of Environmental Research and Public Health, 10(4), 1462-1473. https://doi.org/10.3390/ijerph10041462

Zou, Y. M., Ma, Y., Liu, J. H., Shi, J., Fan, T., Shan, Y. Y., Yao, H. P., \& Dong, Y. L. (2015). Trends and correlation of antibacterial usage and bacterial resistance: time series analysis for antibacterial stewardship in a Chinese teaching hospital (2009-2013). European Journal of Clinical Microbiology \& Infectious Diseases, 34(4), 795-803. https://doi.org/10.1007/s10096-014-2293-6 